\title{
Assessment of the Performance of Membranes Type Koch in Hartha Power Plant
}

\author{
Ala’a Abdulrazaq Jassim \\ Department of Chemical Engineering, University of Basrah, P.O. BOX: 1458 Al-Ashaar mail, Basrah, Iraq \\ Correspondence should be addressed to Ala’a Abdulrazaq Jassim, alaahade88@yahoo.com
}

Received 14 July 2009; Accepted 28 January 2010

Academic Editor: Evans Chirwa

Copyright () 2010 Ala'a Abdulrazaq Jassim. This is an open access article distributed under the Creative Commons Attribution License, which permits unrestricted use, distribution, and reproduction in any medium, provided the original work is properly cited.

This paper deals with the assessment of the performance of reverse osmosis membranes type (TFC-Koch) model (8822XR-365) which are used in water desalination unit in Hartha power plant, one of the electrical power plant in the south Iraq. This unit has a capacity of $100 \mathrm{~m}^{3} / \mathrm{h}$ withdraws water from Shat Al-Arab River as a raw water having total dissolved solid (TDS) > 3000 ppm, and consists of two stages with total recovery and salt rejection of about $60 \%$ and $95 \%$, respectively. The first array contains twelve vessels and the second six vessels. Each vessel contains six elements, 8 inches in diameter and 40 inches in length. The performance of the reverse osmosis (RO) membranes is based on surveying the chemical analysis of different ions present in water for both permeate and rejected streams from the unit log book, and only those readings where the overall recovery was $60 \%$ were selected. The results depicted that the reduction of membrane efficiency is attributed to the membrane blockage due to scaling and fouling. Under high fouling conditions the permeate flow rate is reduced and accordingly a high feed pressure is required to produce the design flow rate of permeate or percent recovery. A simulation of the behavior of RO membranes was conducted using standard Saehane software and compared with predicted model that was developed by the same authors. The results revealed that the reduction in water flow in both elements one and two in each vessel in the first array is attributed to the high permeate water flux through these two elements beyond the operation limits. Accordingly it is necessary to replace these two elements or change their position relative to other elements periodically.

\section{Introduction}

Membrane technology has become of great interest for treatment of different feeds. Depending on the membrane types, materials in the feed and process conditions, the membrane loses its performance with time. A reverse osmosis (RO) desalination system has many advantages in point of saving energy and less installation spaces and has become a favored technology for the production of fresh water.

In Basrah, one of the major industrial cites in the southern Iraq, RO is predominately utilized for the production of desalted water both for drinking and industry including Hartha power plant. This plant has RO unit of capacity $100 \mathrm{~m}^{3} / \mathrm{h}$ and withdraws water from Shat AL-Arab River with TDS $>3000$ ppm.

It is well known that $\mathrm{RO}$ system of recoveries higher than $50 \%$ requires more than one stage in order not to exceed the single element recovery limit. Usually two arrays will suffice for recoveries up to $75 \%$ [1], however, three arrays must be used for higher recoveries up to $87.5 \%$. The rejected water from the first stage is fed to the second stage, while the permeates from all vessels are combined to form the product. Recently, most of RO units use double-pass systems rather than single pass, the advantage of this arrangement is as follows[2].

(1) Production cost for fresh water is reduced by around $15 \%$.

(2) Unit installation space is reduced.

(3) Unit capacity can be easily expanded up to around $15 \%$ by only adding a second stage array.

(4) Disposal of brine water is reduced to about two thirds. 
TABLE 1: General properties of Koch membrane type TFC-8822XR$365 \mathrm{ft}^{2}$.

\begin{tabular}{lc}
\hline Permeate flow rate $\left(\mathrm{m}^{3} / \mathrm{d}\right)$ & 34.1 \\
Chloride rejection \% & 99.7 \\
Membrane area $\left(\mathrm{m}^{2}\right)$ & 33.9 \\
Maximum operation pressure $(\mathrm{kpa})$ & 4140 \\
Maximum operation temperature $\left({ }^{\circ} \mathrm{C}\right)$ & 45 \\
Maximum continuous feed chlorine $(\mathrm{ppm})$ & $<0.1$ \\
Maximum differential pressure per element $(\mathrm{kpa})$ & 69 \\
Maximum differential pressure per vessel $(\mathrm{kpa})$ & 414 \\
Maximum feed turbidity NTU & 1 \\
Maximum feed SDI & 5 \\
Construction Spiral wound with fiberglass outer warp & \\
Application Extra high rejection for brackish water treatment & \\
\hline
\end{tabular}

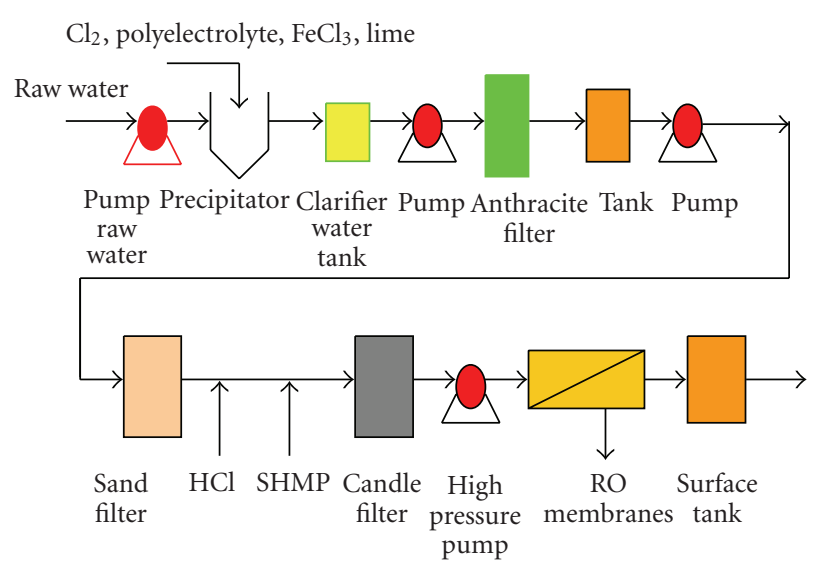

Figure 1: Flow Diagram of RO Plant.

The performance of RO system is influenced by feed pressure, feed water composition, temperature, and percent recovery. For example, a feed temperature drop of $4^{\circ} \mathrm{C}$ will cause a decrease of permeates flow of about $10 \%$ [2].

AbdulSattar et al. [3] studied the effect of applied pressure on the performance of two types of membranes; Koch type (8822-XR) and Saehane type (RE8040BE). They showed that the amount of permeate for Saehane membranes is larger than that for Koch membranes by about $26 \%$. Abdul Sattar et al. [4] developed a mathematical model for evaluating the performance of $\mathrm{RO}$ unit using various types of membranes. El-Manharawy and Hafez [5] studied the effect of percent recovery and feed concentration on the design of $\mathrm{RO}$ units.

In this work the effect of operation time on the performance of Koch membranes type (8822-XR) was studied. The assessments of membranes performance based on water analysis of different ions concentration in both permeate and rejected water with $60 \%$ recovery were considered. The study covered two years of plant operation. A complete set of operating data including permeate flow rates for each array, permeate flux, permeate TDS, and feed pressure for each element were made available from the unit log books.

\section{Plant Process Description}

Feed water is pumped from Shat Al-Arab River to the sedimentation tank to precipitate the large suspended particles by the addition of ferric chloride $\mathrm{FeCl}_{3}$ and polyelectrolyte as a coagulant. The water is then pumped to the precipitator of the lime-soda ash process to remove carbonate hardness as shown by the following equations [6].

$$
\begin{aligned}
& \mathrm{Ca}\left(\mathrm{HCO}_{3}\right)_{2}+\mathrm{Ca}(\mathrm{OH})_{2} \longrightarrow 2 \mathrm{CaCO}_{3}+2 \mathrm{H}_{2} \mathrm{O} \downarrow \\
& \mathrm{Mg}\left(\mathrm{HCO}_{3}\right)_{2}+2 \mathrm{Ca}(\mathrm{OH})_{2} \longrightarrow \mathrm{Mg}(\mathrm{OH})_{2}+2 \mathrm{CaCO}_{3}+2 \mathrm{H}_{2} \mathrm{O} \downarrow \\
& \mathrm{CaSO}_{4}+\mathrm{Na}_{2} \mathrm{CO}_{3} \longrightarrow \mathrm{CaCO}_{3}+\mathrm{Na}_{2} \mathrm{SO}_{4} \downarrow \\
& \mathrm{CaCl}_{2}+\mathrm{Na}_{2} \mathrm{CO}_{3} \longrightarrow \mathrm{CaCO}_{3}+2 \mathrm{NaCl} \downarrow
\end{aligned}
$$

The lime-soda ash process can also reduce the silica concentration, due to the formation of aluminum and iron silicate calcium carbonate when ferric chloride is added as a coagulant [1]. Hypochlorite is added to remove the biological matter. The clarified water is collected in a tank having a capacity of about $50 \mathrm{~m}^{3}$. A booster pump (capacity of $180 \mathrm{~m}^{3} / \mathrm{h}$ and pressure of 5 bars) which draws water from the clarifier tank pumps it through an anthracite filter to remove any dissolved organics and chlorine in water. The output stream from the anthracite filter is collected in a special tank having a capacity of $500 \mathrm{~m}^{3}$. A centrifugal booster pump (capacity $165 \mathrm{~m}^{3} / \mathrm{h}$ and 5 bar pressure) draws water from the water tank and sends it to the polishing filter vessel (sand filter) to remove turbidity and any other impurities. Hydrochloric acid is added to the clarified water to adjust the $\mathrm{pH}$ so as to reduce the risk of precipitating soluble carbonate salts. Sodium hexametaphosphate (SHMP) is also added to the feed water prior to $\mathrm{RO}$ system to provide a further safety against scaling of the membrane by gypsum and other soluble salts. The treated water is passed through a microfilter ( $5 \mu \mathrm{m})$ to remove small particles prior to pumping. The treated water to the $\mathrm{RO}$ membrane vessels utilizes a high pressure pump (capacity $165 \mathrm{~m}^{3} / \mathrm{h}$ and pressure 35 bars). Desalted water or permeate is collected in a service tank (capacity about $150 \mathrm{~m}^{3}$ ) while the waste or rejected water is treated prior to being discharged to the river. A process flow diagram is shown in Figure 1.

Al-Hartha RO unit consists of two stages, the first stage comprises of 12 vessels and the second 6 vessels where each vessel contains six elements (40 inches in length and 8 inches in diameter). The raw water is divided into 12 branches, one for each vessel. The first array of these vessels has a percent recovery of about $40 \%$. The rejected water of the first array is fed to the second array which contains six vessels in parallel arrangement with a recovery of about $20 \%$, which means that the total recovery of the unit is around $60 \%$.

\section{Results and Discussion}

The aim of this work is to assess the performance of Koch membranes type (8822XR-365Koch) of USA origin, which is used in the reverse osmosis unit at the Hartha power plant. 
TABLE 2: Theoretical and experimental values of ions in the rejected stream for fourteen samples.

\begin{tabular}{cccccccccccc}
\hline & \multicolumn{3}{c}{ Theoretical values } & \multicolumn{3}{c}{ Ions concentration ppm } & \multicolumn{3}{c}{ Experimental values } \\
\hline $\mathrm{Ca}^{+2}$ & $\mathrm{Mg}^{+2}$ & $\mathrm{SO}_{4}{ }^{-2}$ & $\mathrm{Cl}^{-1}$ & $\mathrm{TH}$ & $\mathrm{TDS}$ & $\mathrm{Ca}^{+2}$ & $\mathrm{Mg}^{+2}$ & $\mathrm{SO}_{4}{ }^{-2}$ & $\mathrm{Cl}^{-1}$ & $\mathrm{TH}^{2}$ & $\mathrm{TDS}^{2}$ \\
\hline 347.4 & 302.6 & 1186 & 1876 & 650 & 7121 & 444 & 337 & 1649 & 2111 & 781 & 7418 \\
386.8 & 321 & 1813 & 2250 & 707 & 6860 & 435 & 361 & 990 & 1288 & 796 & 7590 \\
405.3 & 342.1 & 1813 & 2813 & 723 & 8476 & 401 & 333 & 1182 & 2681 & 734 & 8280 \\
407.9 & 339.5 & 1931 & 2939 & 747 & 8984 & 401 & 540 & 1436 & 3041 & 941 & 8316 \\
365.8 & 294.7 & 1786 & 2239 & 660 & 6966 & 340 & 291 & 1318 & 2146 & 631 & 6158 \\
326.3 & 255.3 & 1439 & 1739 & 581 & 5210 & 364 & 211 & 1065 & 1671 & 575 & 4488 \\
439.5 & 373.7 & 2131 & 2834 & 813 & 8631 & 359 & 309 & 1418 & 2079 & 663 & 6679 \\
489.5 & 426.3 & 2018 & 3105 & 916 & 9186 & 582 & 302 & 1156 & 3017 & 902 & 8659 \\
610.5 & 434.2 & 1713 & 3158 & 1021 & 10531 & 489 & 361 & 872 & 1263 & 850 & 6389 \\
531.6 & 471.1 & 1745 & 3126 & 1002 & 11342 & 464 & 368 & 1053 & 2574 & 832 & 8560 \\
415.8 & 310.5 & 1700 & 2053 & 7,26 & 7015 & 318 & 265 & 993 & 1928 & 583 & 5227 \\
510.5 & 386.8 & 1602 & 2355 & 907 & 7676 & 420 & 276 & 1120 & 1386 & 696 & 5841 \\
518.4 & 352.6 & 1839 & 2552 & 871 & 8094 & 436 & 330 & 992 & 2265 & 766 & 6668 \\
360.5 & 278.9 & 1792 & 1979 & 660 & 6305 & 396 & 285 & 1102 & 1386 & 679 & 6060 \\
\hline
\end{tabular}

TABLE 3: General properties for production in array 1 and 2.

\begin{tabular}{lccccc}
\hline Array & Pressure bar & Permeate flow rate $\mathrm{m}^{3} / \mathrm{h}$ & Concentrate flow $\mathrm{m}^{3} / \mathrm{h}$ & Permeate TDS $(\mathrm{ppm})$ & Concentrate TDS $(\mathrm{ppm})$ \\
\hline 1 & 14.8 & 77.2 & 82.8 & 19.21 & 4507 \\
2 & 12.3 & 22.8 & 60.4 & 50.72 & 6164 \\
\hline
\end{tabular}

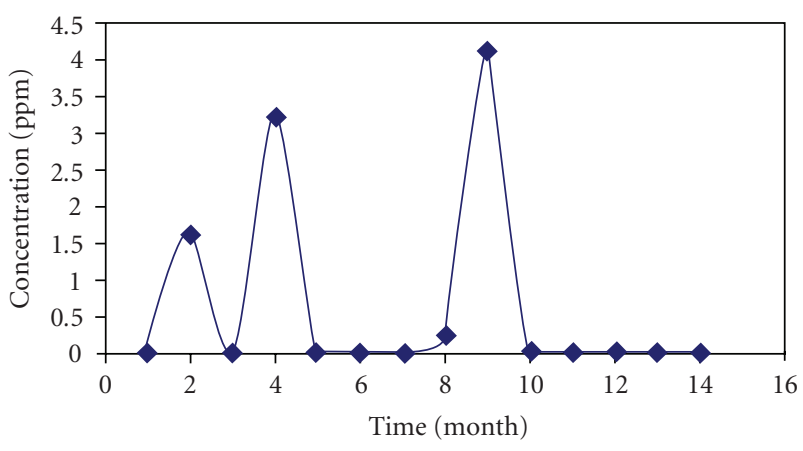

FIgURE 2: Ca ion concentration in the permeate.

The chemical analyses were derived from the log book of the unit, all having recoveries of $60 \%$. Chemical analysis for (14) samples was collected from permeates and rejected streams.

The chemical compositions of the concentrated streams (rejected water) can be estimated from the material balance based on the composition of various ions in the feed water and the percent recovery. The Concentration factors as follows [1]:

$$
\mathrm{CF}=\frac{1}{(1-R)}
$$

where $R$ is the percent recovery.

Table 1 shows the properties of Koch membranes type TFC-8822XR. Membrane efficiency depends on the variation of the ions concentration through the permeate stream

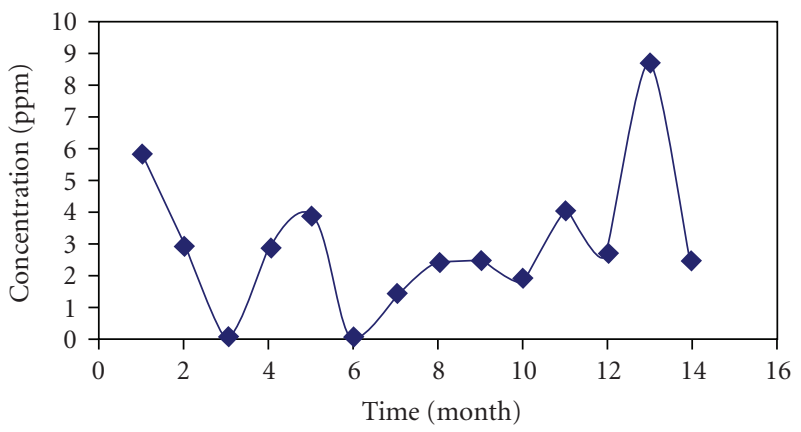

FIgURE 3: Mg ion concentration in the permeate.

which reflects membrane fouling and scaling problems, due to the deposition of such ions on the membrane surface.

Figures 2-7 show the concentration of profiles $\mathrm{Ca}^{+2}$, $\mathrm{Mg}^{+2}, \mathrm{SO}_{4}{ }^{-2}, \mathrm{Cl}^{-}, \mathrm{TH}$ (Total Hardness), and TDS (Total Dissolved Solids) in $\mathrm{mg} / \mathrm{l}$ for the permeate stream as a function of operation time in months. It can be seen that the concentrations of these various ions increase with time and they decrease and reach zero value after chemical cleaning.

The increase in the ions concentration in the permeate stream with operation time may be attributed to the membrane blocking by both calcium sulphate and organic substances. The effect of concentration polarization could be another reason for increased salinity in the permeate flow rate.

The effect of concentration polarization is specifically felt near the membrane surface and is considered as a major 
TABLE 4: Total results in details for the theoretical properties of each element in arrays 1 and 2.

\begin{tabular}{|c|c|c|c|c|c|c|c|}
\hline Array & El. No. & Feed Pressure bar & Feed $\mathrm{m}^{3} / \mathrm{h}$ & Permeate $\mathrm{m}^{3} / \mathrm{h}$ & Recovery & Feed TDS (ppm) & Permeate TDS (ppm) \\
\hline \multirow{6}{*}{1} & 1 & 14.8 & 13.3 & 1.2 & 0.093 & 2342 & 12.4 \\
\hline & 2 & 14.3 & 12.1 & 1.2 & 0.096 & 2580 & 14.6 \\
\hline & 3 & 13.8 & 10.9 & 1.1 & 0.101 & 2853 & 17.2 \\
\hline & 4 & 13.4 & 9.8 & 1.0 & 0.106 & 3170 & 20.4 \\
\hline & 5 & 13.1 & 8.8 & 1.0 & 0.111 & 3542 & 24.5 \\
\hline & 6 & 12.9 & 7.8 & 0.9 & 0.117 & 3982 & 29.6 \\
\hline \multirow{6}{*}{2} & 1 & 12.3 & 13.8 & 0.8 & 0.058 & 4507 & 34.7 \\
\hline & 2 & 11.8 & 13 & 0.7 & 0.056 & 4782 & 40.6 \\
\hline & 3 & 11.3 & 12.3 & 0.7 & 0.053 & 5061 & 47.5 \\
\hline & 4 & 10.8 & 11.6 & 0.6 & 0.950 & 5342 & 55.6 \\
\hline & 5 & 10.4 & 11 & 0.5 & 0.047 & 5621 & 65.1 \\
\hline & 6 & 10 & 10.5 & 0.5 & 0.044 & 5897 & 76.5 \\
\hline
\end{tabular}

TABLE 5: Total results in details for the theoretical properties of each element in arrays 1 and 2 using Saehane software.

\begin{tabular}{|c|c|c|c|c|c|c|c|}
\hline Array & El. No. & Feed Pressure bar & Feed $\mathrm{m}^{3} / \mathrm{h}$ & Permeate $\mathrm{m}^{3} / \mathrm{h}$ & Recovery & Feed TDS (ppm) & Permeate TDS (ppm) \\
\hline \multirow{6}{*}{1} & 1 & 15.5 & 13.9 & 1.2 & 0.09 & 3282.8 & 15.7 \\
\hline & 2 & 14.9 & 12.6 & 1.2 & 0.093 & 3605.6 & 18.5 \\
\hline & 3 & 14.5 & 11.5 & 1.1 & 0.096 & 3972.4 & 21.8 \\
\hline & 4 & 14.1 & 10.4 & 1.0 & 0.1 & 4392.5 & 25.8 \\
\hline & 5 & 13.7 & 9.3 & 1.0 & 0.104 & 4877.1 & 30.8 \\
\hline & 6 & 13.4 & 8.4 & 0.9 & 0.108 & 5440.0 & 37.0 \\
\hline \multirow{6}{*}{2} & 1 & 12.9 & 14.9 & 0.8 & 0.053 & 6097.5 & 42.8 \\
\hline & 2 & 12.2 & 14.1 & 0.7 & 0.051 & 6439.4 & 50.1 \\
\hline & 3 & 11.6 & 13.4 & 0.7 & 0.048 & 6780.1 & 58.8 \\
\hline & 4 & 11.1 & 12.8 & 0.6 & 0.044 & 7116.0 & 69.0 \\
\hline & 5 & 10.6 & 12.2 & 0.5 & 0.41 & 7443.2 & 81.1 \\
\hline & 6 & 10.2 & 11.7 & 0.4 & 0.037 & 7757.9 & 95.6 \\
\hline
\end{tabular}

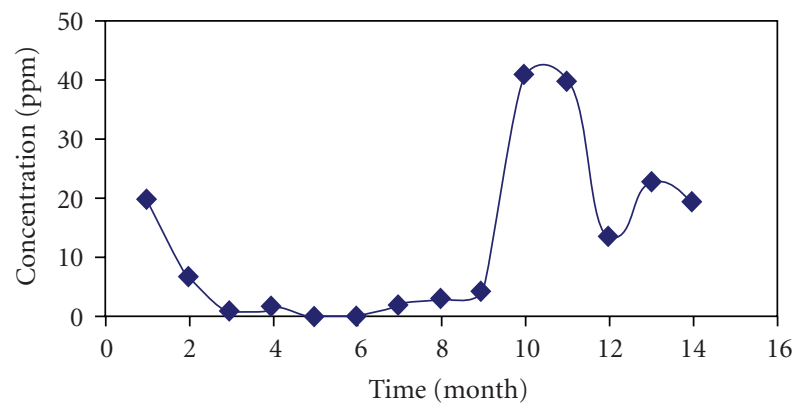

FIGURE 4: $\mathrm{SO}_{4}$ ion concentration in the permeate.

reason for the increased ions concentration in the permeate stream. The effect of concentration polarization increases osmotic pressure, leading to a reduction of net driving pressure differential across the membrane and hence reducing the product flow rate and increasing the scale potential. In order to compensate for such adverse effects, higher pressure should be applied. Table 2 shows the ions concentrations in the rejected stream, both experimentally and theoretically.

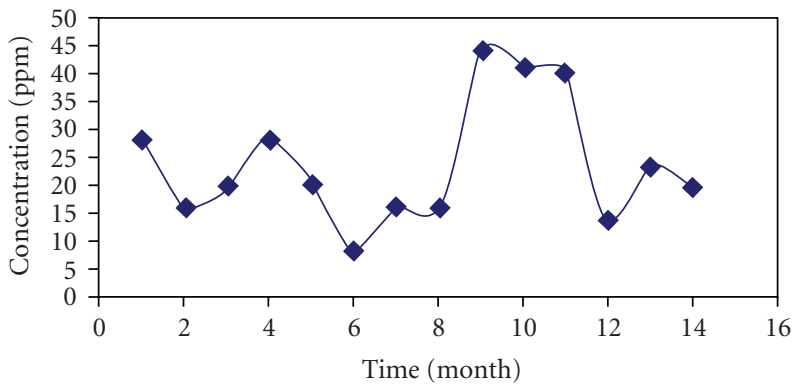

FIGURE 5: $\mathrm{Cl}$ ion concentration in the permeate.

A simulation run using Saehane software was conducted in order to investigate the performance of each individual element. It was observed that during the unit operation history, the performance of some membrane modules started to deteriorate with time due to scale formation and fouling deposition on the surface of the membranes. Cleaning therefore became necessary to improve the performance of the membranes. Cleaning gives a great improvement in both the quality and quantity of the permeate stream. This is 


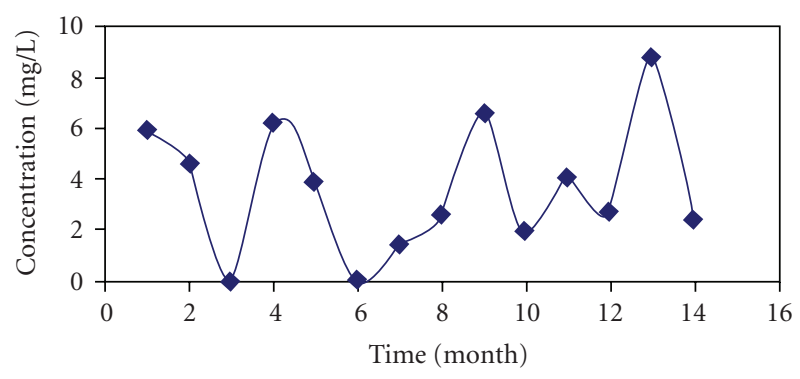

FIgURE 6: Total hardness concentration in the permeate.

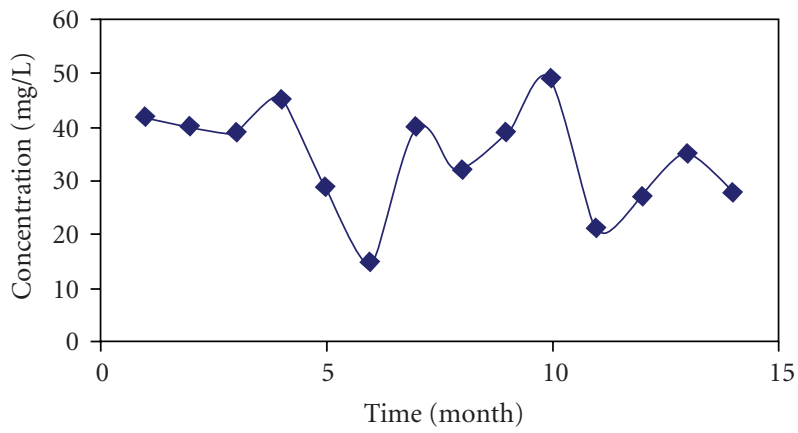

Figure 7: Total dissolved solids concentration in the permeate.

evident from Figures 2, 3, 4, 5, 6, and 7 which show the improvement of membrane efficiency after chemical cleaning especially after three and six months of operation.

The cleaning agent, composed of $0.1 \%$ Sodium Triphosphate, $1 \% \mathrm{Na}_{4}$ EDTA,s and 2\% Citric Acid, was used for chemical cleaning to remove both organic and inorganic salts. Table 3 shows the overall properties for the influent streams from the arrays one and two, while Table 4 shows the theoretical results for each element using the program that was developed previously by the same authors [4]. Table 5 revealed the theoretical values for each element using Saehane software.

The degradation of elements one and two for each vessel in the first array of the RO unit in Hartha power plant is attributed to the mechanical damage. This is due to the increasing of the permeate flux relative to the standard flux. Accordingly, the replacement of elements one and two or change of position relative to other elements is required to improve the permeate quality.

\section{Conclusions}

A simulation of the behavior of RO membranes was conducted using standard Saehane software and compared with predicted model that was developed by the authors. The results revealed that the reduction in water flow in both elements one and two in each vessel in the first array is attributed to the high permeate water flux through these two elements beyond the operation limits. Accordingly it is necessary to replace these two elements or change their position relative to other elements periodically.

\section{References}

[1] Technical Manual, Saehane Company, http://www.saehancsm .com/.

[2] M. Kurihara, H. Yamamura, and T. Nskanishi, "High recovery/high pressure membranes for brine conversion SWRO process development and its performance data," Desalination, no. 125 , p. $9,1999$.

[3] K. AbdulSattar, S. Ismail, and A. A. Jassim, "Effect of different operation pressures for various membranes on the performance of RO plants," Desalination, vol. 155, no. 3, pp. 287-291, 2003.

[4] K. AbdulSattar, S. Ismail, and A. A. Jassim, "Modeling of reverse osmosis systems," Desalination, vol. 158, no. 1-3, pp. 323-329, 2003.

[5] S. El-Manharawy and A. Hafez, "Water type and guidelines for RO system design,” Desalination, vol. 139, no. 1-3, pp. 97-113, 2001.

[6] I. S. AL-Mutiz, M. A. AL-Ghunaimi, A. AL-Mutlag, et al., "A comparison of theoretically calculated and actual chemical dose at water treatment plants," in Proceedings of the 4th Gulf Water Conference, pp. 1-10, Manama, Bahrain, 1999. 

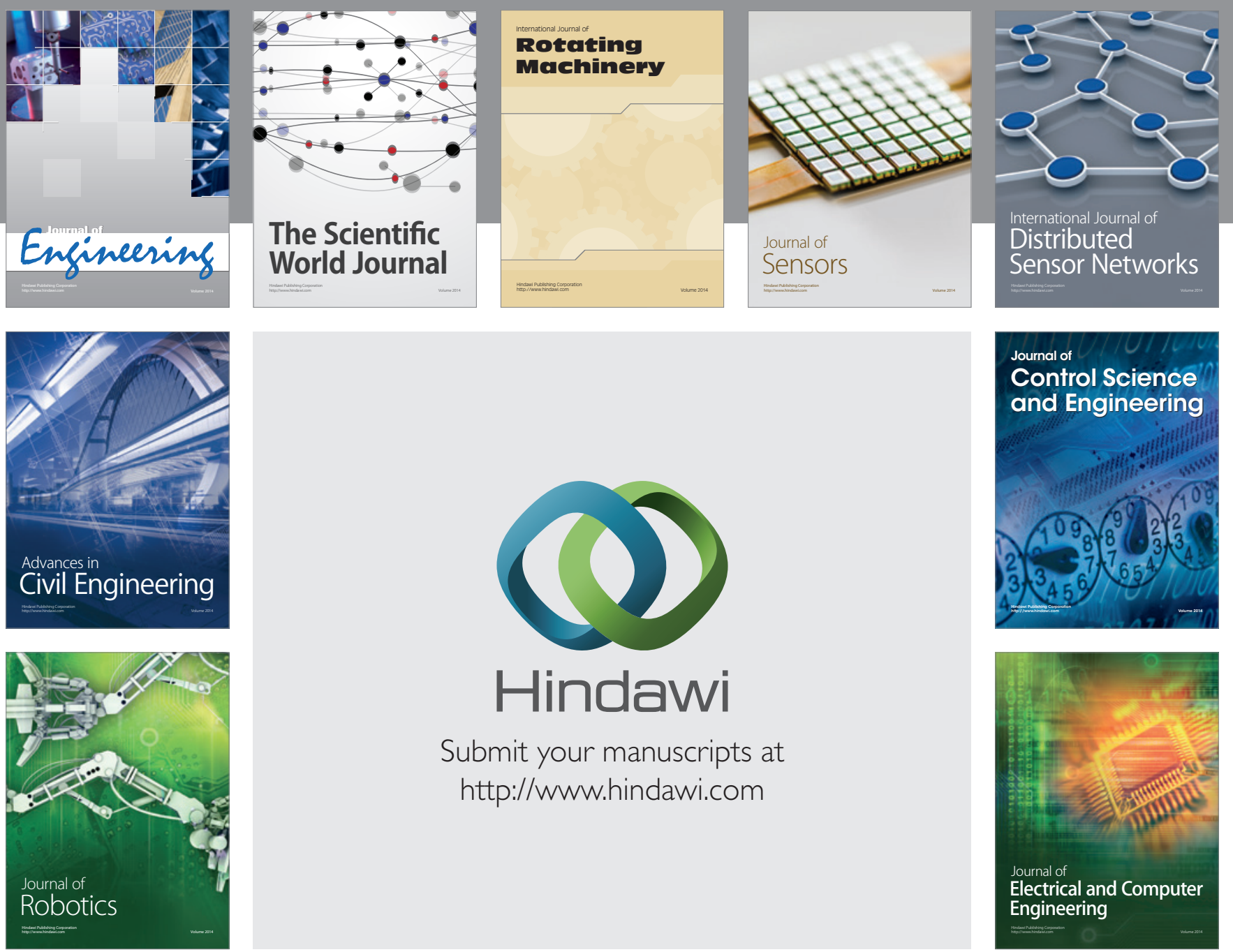

Submit your manuscripts at

http://www.hindawi.com
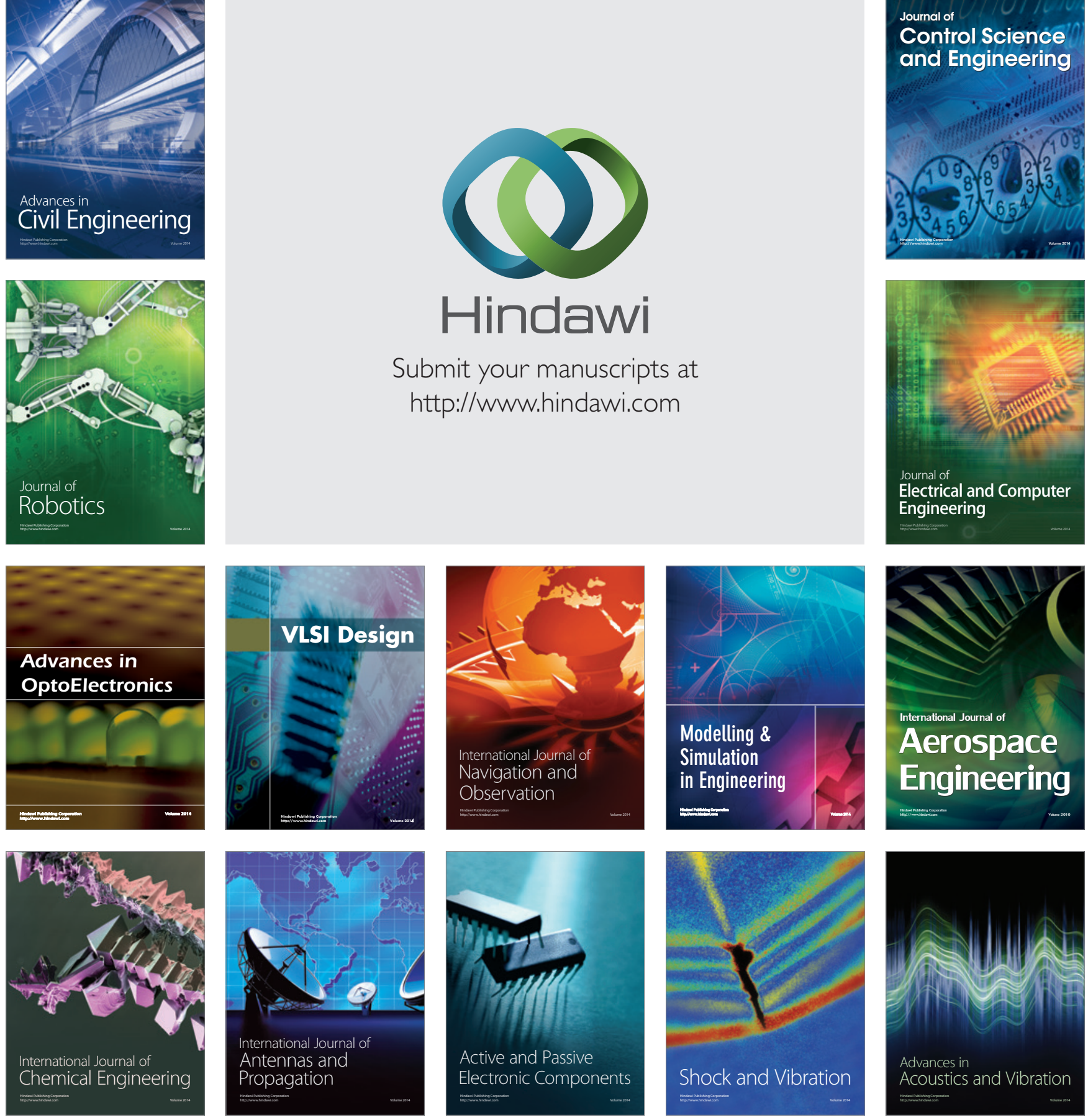